\title{
Aircraft-based operation of an aerosol mass spectrometer: Measurements of tropospheric aerosol composition
}

\author{
Johannes Schneider ${ }^{\mathrm{a}, *}$, Silke S. Hings ${ }^{\mathrm{a}}$, B. Nele Hock ${ }^{\mathrm{a}}$, \\ Silke Weimer ${ }^{\mathrm{a}, 1}$, Stephan Borrmann ${ }^{\mathrm{a}, \mathrm{b}}$, Markus Fiebig ${ }^{\mathrm{c}}$, Andreas Petzold ${ }^{\mathrm{c}}$, \\ Reinhold Busen ${ }^{\mathrm{c}}$, Bernd Kärcher ${ }^{\mathrm{c}}$ \\ a Particle Chemistry Department, Max Planck Institute for Chemistry, Mainz, Germany \\ ${ }^{\mathrm{b}}$ Institute for Atmospheric Physics, Johannes Gutenberg University, Mainz, Germany \\ ${ }^{\mathrm{c}}$ Institut für Physik der Atmosphäre, Deutsches Zentrum für Luft- und Raumfahrt, Oberpfaffenhofen, \\ D - 82234 Wessling, Germany
}

Received 12 April 2005; received in revised form 14 July 2005; accepted 14 July 2005

\begin{abstract}
The Aerodyne quadrupole aerosol mass spectrometer was deployed on the Falcon twin jet research aircraft operated by Deutsches Zentrum für Luft- und Raumfahrt (DLR). This was the first deployment of an AMS in a jet aircraft. Aerosol mass concentration measurements in the troposphere up to altitudes of about $11 \mathrm{~km}$ were performed within two measurement flights on 12 and 14 May 2003 over southern Germany. Background aerosol data were gained up to $6 \mathrm{~km}$, while aircraft exhaust aerosol was be sampled at higher altitudes on 14 May, indicating the presence of sulfuric acid and unburned hydrocarbons in the exhaust particles. The boundary layer aerosol on 12 May was found to be composed of $49 \%$ organics, $12 \%$ sulfate, $15 \%$ ammonium, and $24 \%$ nitrate by mass. The upper edge of the boundary layer was marked by a sharp decrease of nitrate and ammonium at an altitude of $3 \mathrm{~km}$, while sulfate and organics decreased to a much lesser degree. On 14 May, the boundary layer aerosol was composed of $23 \%$ organics, $20 \%$ sulfate, $24 \%$ ammonium, and $33 \%$ nitrate by mass, and the boundary layer reached up to about $5000 \mathrm{~m}$ and had no sharp upper edge. The size distributions indicated internal mixtures of ammonium sulfate and -nitrate in the boundary layer, while the organics were externally mixed. Additionally, a smaller mode consisting
\end{abstract}

\footnotetext{
* Corresponding author. Tel.: +496131 305586; fax: +496131305597.

E-mail address: schneider@mpch-mainz.mpg.de (J. Schneider).

${ }^{1}$ Present address: EMPA, CH-8600 Dübendorf, Switzerland and Paul Scherrer Institute, CH-5232 Villigen, Switzerland.
} 
only of ammonium sulfate, was detected. This bimodal structure of ammonium sulfate was also detected above the boundary layer in $6 \mathrm{~km}$ altitude on 14 May.

(c) 2005 Elsevier Ltd. All rights reserved.

Keywords: Aircraft measurements; Aerosol chemical composition; Aerosol mass spectrometry

\section{Introduction}

The fine mode aerosol $(D<1 \mu \mathrm{m})$ in the planetary boundary layer is dominated by anthropogenic aerosol components such as sulfate, nitrate, carbonaceous compounds (elemental carbon, EC, organic carbon, OC), and ammonium, e.g. Seinfeld and Pandis (1998). In the free troposphere, the aerosol background is lower, and it is thought that sulfuric acid and water are major components of the background aerosol, with additional components that are imported by vertical transport from the boundary layer. More recent single particle mass spectrometric studies have demonstrated that in addition to sulfates, organic compounds are commonly found in tropospheric aerosol particles (Murphy, Thomson, \& Mahoney, 1998).

In the upper troposphere, cirrus clouds may be influenced by aircraft exhaust particles at cruise altitudes. Aircraft exhaust particles are mainly composed of soot and sulfuric acid (Brock et al., 2000; Curtius et al., 1998; Schröder et al., 2000; Schumann et al., 2002). Also, unburned hydrocarbons can condense on the soot or sulfuric acid particles (Kärcher, Yu, Schröder, \& Turco, 1998; Yu, Turco, Kärcher, \& Schröder, 1998). The volatile particles in the young plumes (plume ages $\leqslant 3 \mathrm{~s}$ ) have been found to be as small as a few $\mathrm{nm}$ while the soot particles are between 10 and $500 \mathrm{~nm}$ in diameter. Larger aircraft-produced particles $(1-10 \mu \mathrm{m})$ are thought to be contrail ice crystals (Petzold et al., 1997; Schröder et al., 2000). Besides their crucial role in contrail formation soot particles that have been activated by sulfuric acid to take up water may trigger the formation of ice crystals in cirrus clouds via homogeneous and heterogeneous freezing (Ettner, Mitra, \& Borrmann, 2004).

While there are numerous ground-based measurements of the chemical composition of aerosol particles, chemically resolved vertical aerosol profiles are sparse. This is mainly due to experimental limitation: Off-line methods like filter sampling suffer from artifacts like evaporation of volatile species from the filters during sampling or the reaction of certain organics species (e.g. with the $\mathrm{OH}$ radical) during the sampling. Also, a long sampling time is needed, and therefore the temporal resolution is limited. This is especially a drawback in aircraft-based measurements since the spatial variability of the aerosol particles may be high due to local sources and short lifetime. Only recently, a few aircraft-based studies have been reported. During the PEM-West B, the SUCCESS, and the SONEX experiments, Dibb et al. (1997), Dibb, Talbot, and Loomis (1998), Dibb et al. (1999) performed composition measurements by sampling on Teflon filters with subsequent ion chromatographic (IC) analysis. Lee et al. (2003) report on aircraftbased measurements using the novel particle into liquid sampler (PILS) during ACE-Asia and TRACE-P. The PILS technique allows a much better time resolution (4 min) compared to the filter samples (typically $20 \mathrm{~min}$ ). Kline et al. (2004) report on size-resolved particle composition measurements using a microorifice impactor (MOI) during the ACE-Asia project. An intercomparison between PILS-IC and filter based IC analysis during TRACE-P and ACE-Asia that has been reported by Moore et al. (2004), yielded good agreement between both techniques for the fine mode aerosol. 
A fast on-line method that allows the quantitative measurement of aerosol sulfate, nitrate, ammonium and organic carbon is the quadrupole aerosol mass spectrometer (Q-AMS), which was developed by Aerodyne Research, Inc. (Jayne et al., 2000). This technique allows a time resolution of about $1 \mathrm{~min}$ and has first been applied in an aircraft by Bahreini et al. (2003), who performed measurements during ACE-Asia over the eastern Pacific Ocean at altitudes up to $3.5 \mathrm{~km}$. Here, we present first measurements with the Q-AMS in a twin jet aircraft covering altitudes up to $11 \mathrm{~km}$ that were performed within the research project DLR-PAZI (Particles from Aircraft: Impact on Cirrus Clouds and Climate).

\section{Measurements}

Within the PAZI campaign, the Q-AMS was deployed on the DLR research aircraft Falcon which is capable of reaching the upper troposphere and lower stratosphere. The measurements took place in May 2003 over Southern Germany at latitudes between 47 and $50^{\circ} \mathrm{N}$ and longitudes between 10 and $14^{\circ} \mathrm{E}$. The aircraft was based at the airport of DLR at Oberpfaffenhofen. Four measurement flights were performed with the Q-AMS including sampling in aircraft exhaust at cruising altitude as well as background flights in regions with little air traffic.

Here we report on data of two flights, on 12 and 14 May 2003. The measurement flight on 12 May was solely dedicated to background aerosol measurements between the ground level and the tropopause, while on 14 May, additional measurements took place in the wake of commercial jet aircraft at cruise altitude. During the remaining two flights (20 and 22 May) the AMS was operating with lower sensitivity due to a electron multiplier failure and therefore the signal-to-noise ratio of these data is too low to allow reasonable data analysis.

\subsection{Aircraft operation of the quadrupole aerosol mass spectrometer (Q-AMS)}

Fig. 1 gives a schematic of the Q-AMS setup in the Falcon aircraft. The Q-AMS has been described in detail before (e.g. Allan et al., 2003; Jayne et al., 2000; Jimenez, Jayne et al., 2003), so the general concept will be only briefly reviewed here: aerosol particles with diameters between 20 and $1500 \mathrm{~nm}$ are focused onto a narrow beam by means of an aerodynamic lens and are separated from the gas by differential pumping. The lens transmission is approximately $100 \%$ for particles with diameters between 80 and $600 \mathrm{~nm}$. After a flight distance of $390 \mathrm{~mm}$ inside the vacuum chamber they are flash-vaporized on a hot surface, operated at $580^{\circ} \mathrm{C}$ during the measurements presented here. This procedure evaporates the volatile and semi-volatile (non-refractory) compounds of the aerosol. The molecules are ionized by electron impact $(70 \mathrm{eV})$ and analyzed by a quadrupole mass spectrometer. Since the evaporation and ionization processes are separated and linear the instrument can be used for quantitative detection of aerosol components like sulfate, nitrate, ammonium, and organic matter. The Q-AMS can be operated in two modes:

1. The mass spectrum $(M S)$ mode: The particle beam is constantly analyzed and the whole mass range of the spectrometer (160 amu during these measurements) is scanned with a repetition rate of $3 \mathrm{~Hz}$. This mode is used for total chemical composition measurement. 


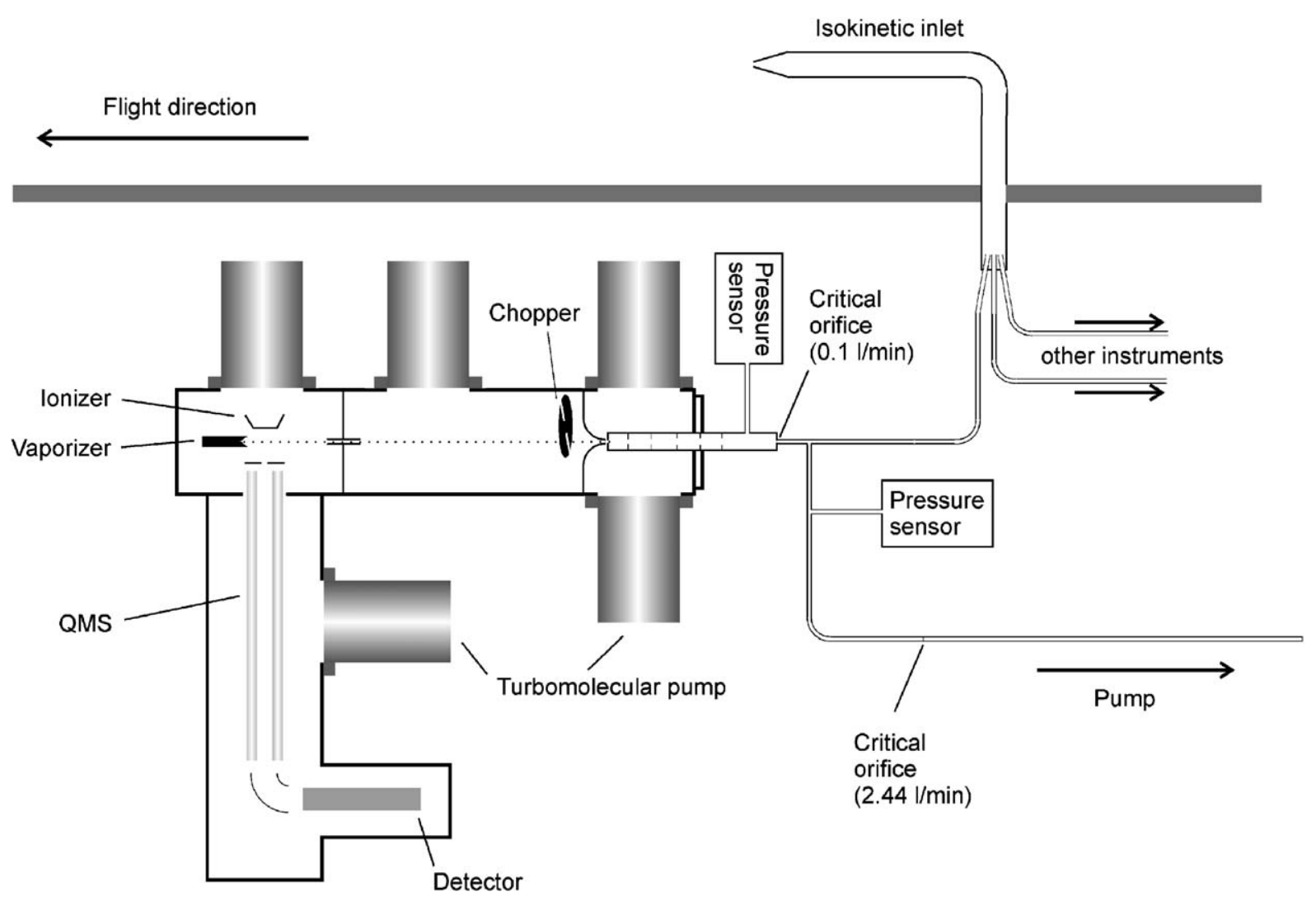

Fig. 1. Schematic of the AMS inside the Falcon aircraft.

2. The time-of-flight (TOF) mode: The particle beam is chopped at a frequency of about $180 \mathrm{~Hz}$, and the mass spectrometer is set onto specific masses. By triggering the MS with the opening of the chopper the size selective mass loading of the individual species can be measured.

The chopper mechanism is also used for complete blocking of the beam to determine the gas-phase background. Both modes of operation were used during these measurement flights, alternating every $10 \mathrm{~s}$ and saving data every $60 \mathrm{~s}$.

In the TOF mode, particle sizing is performed by measuring the time-of-flight between the opening of the chopper and the detection of the particle in the mass spectrometer. The measured diameter is the so-called "vacuum aerodynamic diameter" introduced by Jimenez, Bahreini et al. (2003) as

$$
D_{\mathrm{va}}=\frac{\rho}{\rho_{0}} \frac{1}{\chi} D_{\mathrm{v}},
$$

where $\chi$ is the dynamic shape factor, $\rho$ is the density of the particle, $\rho_{0}$ the density of water $\left(1 \mathrm{~g} / \mathrm{cm}^{3}\right)$ and $D_{\mathrm{v}}$ the volume equivalent diameter.

The relation between $D_{\mathrm{va}}$ and the particle velocity is dependent on the ambient pressure: the acceleration of the particles in the last orifice of the aerodynamic lens (which acts as a critical orifice) is a function 


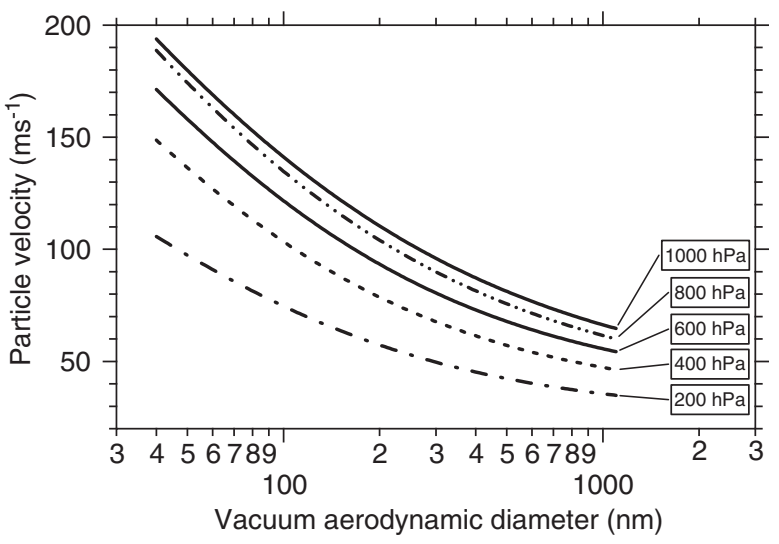

Fig. 2. Velocity calibration at various ambient pressures.

of the pressure difference between the lens pressure and the pressure in the first vacuum chamber. The lens pressure, in turn, is a function of the ambient pressure. Fig. 2 shows the relationship between the particle velocity and the vacuum aerodynamic diameter $D_{\text {va }}$ for various ambient pressures, obtained from laboratory measurements with PSL and ammonium nitrate particles. During aircraft operation, the pressure in the sampling line was continuously monitored, allowing the correct size determination for every pressure level.

The aerosol inlet (Fig. 3a) was described by Fiebig (2001). It is mounted on top of the research aircraft and extends $30 \mathrm{~cm}$ from the aircraft fuselage, thereby reaching out of the boundary layer of the aircraft. The air flows through the tube driven by the movement of the aircraft. The flow is decelerated by a conical diffuser, and the aerosol is sampled through an isokinetic probe. The upper cut-off diameter of the isokinetic probe is larger than $1.3 \mu \mathrm{m}$ for altitudes up to $12 \mathrm{~km}$ (Fig. 3b), which corresponds well to the sampling size range of the Q-AMS.

Inside the aircraft, the airflow is split into the different sampling lines (stainless steel tubes with OD of $\left.1 / 4^{\prime \prime}\right)$, which are regulated by critical orifices. The sample air was passed to the Q-AMS through a tube with a length of about $2 \mathrm{~m}$ with a flow of $2.41 / \mathrm{min}(3.1 \mathrm{~m} / \mathrm{s})$. The Q-AMS samples the particles through a critical orifice $(100 \mu \mathrm{m})$, at a nominal volumetric flow rate of $1.4 \mathrm{~cm}^{3} / \mathrm{s}$. Although the flow tube was thermally insulated, the measured temperature at the Q-AMS inlet was equal to the cabin temperature (298-301 K).

\subsection{Quantification of aerosol mass concentration}

The mass concentration $C_{S}$ of an aerosol species $S$ is calculated by

$$
C_{S}=\frac{\mathrm{MW}_{S}}{\mathrm{IE}_{S} Q N_{\mathrm{A}}} \sum I_{S},
$$

where $\mathrm{IE}_{S}$ is the ionization efficiency of the species $S, Q$ is the volumetric inlet flow rate, $\mathrm{MW}_{S}$ is the molecular weight of the species $S, N_{\mathrm{A}}$ is Avogadro's number, and $\sum I_{S}$ is sum of the detected ion rates belonging to species $S$ (Allan et al., 2003; Allan, Bower et al., 2004; Jimenez, Jayne et al., 2003). The ionization efficiency, i.e. the ratio of ionized and detected molecules of one species in a particle to the total 

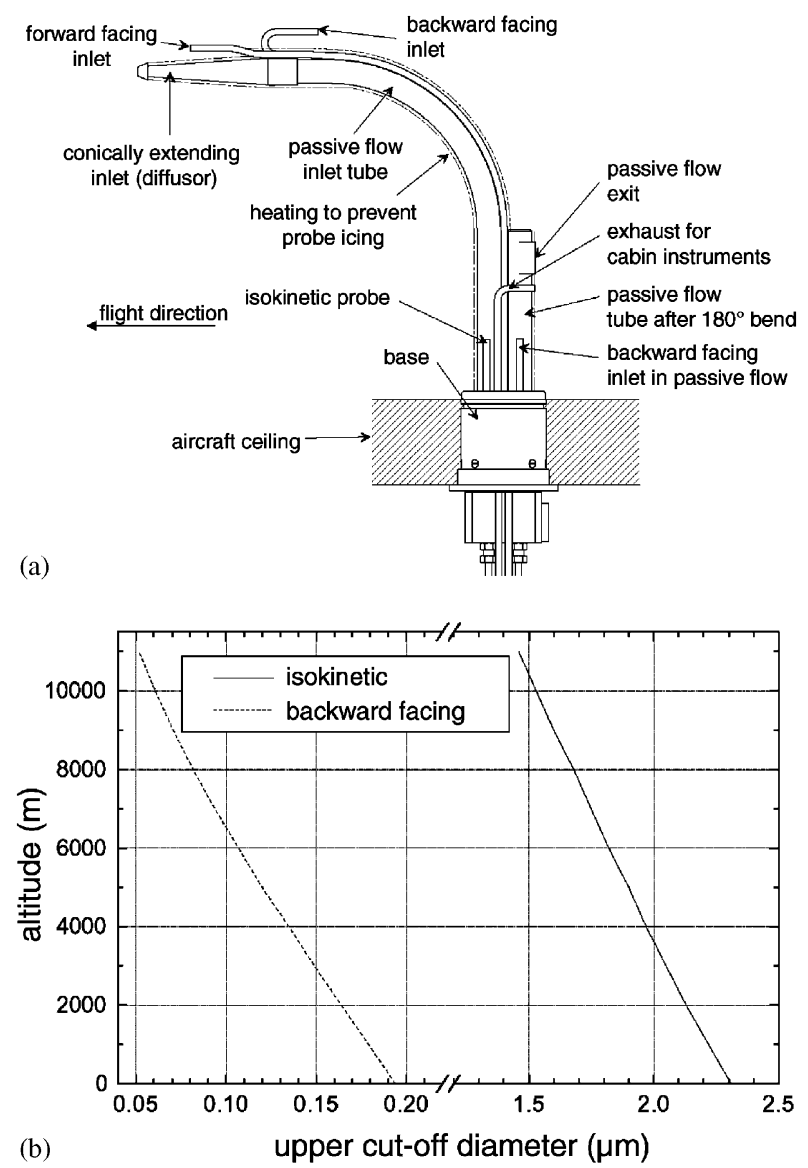

Fig. 3. Design and characteristics of the aircraft inlet, as described by Fiebig (2001).

number of molecules of the species in the particle, is determined for nitrate and ammonium by instrument calibrations with ammonium nitrate. Concentrations of other species are determined using the relative ionization efficiencies compared to nitrate $\left(\mathrm{RIE}_{S}\right)$, so that Eq. (2) becomes

$$
C_{S}=\frac{\mathrm{MW}_{\mathrm{NO}_{3}}}{\mathrm{RIE}_{S} \mathrm{IE}_{S} Q N_{\mathrm{A}}} \sum I_{S}
$$

(Allan, Bower et al., 2004).

The IE's are dependent on the ionization in the high vacuum region of the instrument, where the pressure $\left(<10^{-6} \mathrm{hPa}\right)$ is independent of the ambient conditions. The volumetric inlet flow rate $Q$ is also independent on ambient pressure since it is regulated by the $100 \mu \mathrm{m}$ critical orifice in front of the aerodynamic lens. Thus, Eq. (3) can directly be used to infer mass concentrations referring to ambient pressure.

Possible changes in the sensitivity of the electron multiplier, however, have to be accounted for. Since the instrument had to be operated under relatively low vacuum conditions $\left(10^{-7} \mathrm{hPa}<p<10^{-6} \mathrm{hPa}\right.$ instead of $10^{-8} \mathrm{hPa}<p<10^{-7} \mathrm{hPa}$ ) due to short pumping times before the flights, the multiplier was 


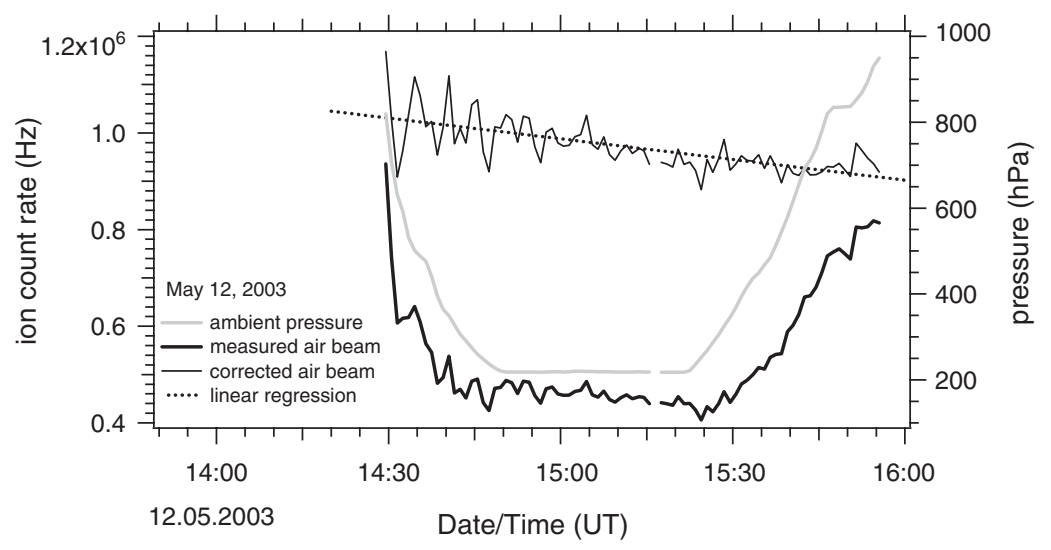

Fig. 4. Air beam reference signal during the flight on 12 May and pressure correction.

notably aging during one flight. Usually, the ion signal at $m / z 28$ or 32 from air molecules is used to determine the aging of the multiplier (Allan et al., 2003). The quantification of mass concentrations refers to this so-called "air beam signal" measured during the ammonium nitrate calibration. Since the air beam signal is decreasing with ambient pressure (the mass concentration of the air is proportional to the ambient pressure), this pressure dependence has to be corrected before determination of the signal decrease due to multiplier aging (Bahreini et al., 2003). The dependence of the air beam signal on ambient pressure has been determined in the laboratory for pressures between 50 and $1000 \mathrm{hPa}$, and the recorded air beam signal during the flight has been corrected for the pressure dependence. As an example, Fig. 4 gives this correction for the flight on 12 May. The remaining decreasing trend in the corrected air beam signal is due to multiplier aging and the inferred mass concentrations have been corrected for this decrease in multiplier performance using the linear fit displayed in Fig. 4.

The statistical error of the count rate of an ion signal in the mass spectrum is determined by the ion count rate which follows the Poisson statistics. Additionally, the single ion signals can be described by a Gaussian distribution with a width of about 0.7 (Allan et al., 2003). This error is determined solely by the ion counts detected at the multiplier and is therefore independent of the ambient pressure. The detection limit decreases with increasing sampling time since it is determined by the statistical noise. The detection limits for $1 \mathrm{~min}$ sampling and $5 \mathrm{~min}$ sampling intervals are given in Table 1 . Since the time when power was available directly prior to the measurement flight was restricted to a few hours the detection limits are higher than during usual AMS-operation.

\subsection{Collection efficiencies $(C E)$}

It has been found in several field studies that the Q-AMS underestimates aerosol mass concentrations by approximately a factor of 2 under low relative humidity conditions (e.g. Alfarra et al., 2004; Allan, Coe et al., 2004; Drewnick et al., 2003; Hogrefe, Drewnick, Lala, Schwab, \& Demerjian, 2004; Schneider et al., 2004). This effect had at first been attributed to lower focusing efficiency of the aerodynamic lens due to irregular particle shape. However, it has recently been recognized that this effect is due to particle 
Table 1

Detection limits in $\mu \mathrm{g} / \mathrm{m}^{3}$ for the individual species for sampling times of 1 and $5 \mathrm{~min}$

\begin{tabular}{llr}
\hline Species & \multicolumn{2}{l}{ Detection limits $\left(\mu \mathrm{g} / \mathrm{m}^{3}\right)$} \\
\cline { 2 - 3 } & $1 \mathrm{~min}$ & $5 \mathrm{~min}$ \\
\hline $\mathrm{SO}_{4}$ & 0.48 & 0.22 \\
$\mathrm{NO}_{3}$ & 0.32 & 0.15 \\
$\mathrm{NH}_{4}$ & 1.68 & 0.75 \\
Org & 1.49 & 0.67 \\
\hline
\end{tabular}

bounce on the vaporizer surface instead of low focusing efficiency. The dependence on relative humidity has been observed in the field by Allan, Coe et al. (2004) and Alfarra et al. (2004). According to these studies, the collection efficiency of the Q-AMS increases from 0.5 to almost 1 under humid conditions, which can be achieved for example with a cooled inlet system.

In our experiment, relative humidity and temperature at ambient conditions have been monitored by the aircraft data acquisition system, and the temperature of the thermally insulated sampling line to the Q-AMS was recorded by the Q-AMS data acquisition. Since the sampling line had a length of about $2 \mathrm{~m}$, we expect that the sample air has warmed up to the temperature of the sampling tube, which was equal to cabin temperature (approx. $300 \mathrm{~K}$ ). This implies that the relative humidity, although occasionally reaching ambient values of more that $100 \%$, remained low inside the sampling tube and was never higher that $25 \%$. Thus, we applied a collection efficiency with respect to particle bounce $\left(\mathrm{CE}_{\mathrm{B}}\right)$ of 0.5 to our data. This value of $\mathrm{CE}_{\mathrm{B}}$ was applied to all species. The assumption of a constant collection efficiency independent on altitude and time may well be an oversimplification, but for the flights presented here no chemically resolved aerosol measurements were available that could have been used to infer time or altitude dependent $\mathrm{CE}_{\mathrm{B}}$ values.

Further effects that can decrease the collection efficiency of aerosol particles by the Q-AMS include:

1. Pressure-dependent transmission of the aerodynamic lens. As described by Zhang et al. (2004), the focusing of the lens is reduced when the working pressure is reduced, while the transmission of smaller particles increases.

2. In addition to the lens pressure, the particle shape can also reduce the focusing of the particle beam, resulting in an incomplete overlap of vaporizer and particle beam for non-spherical particles (Huffman et al., 2005).

However, these effects are regarded to be of minor importance compared to the above-described particle bounce effect.

\subsection{Determination of the ammonium mass concentration}

Ammonium compounds in the aerosol particles can be detected using the mass peaks at $m / z=15\left(\mathrm{NH}^{+}\right)$ and $16\left(\mathrm{NH}_{2}^{+}\right)$. However, the quantification of ammonium is hindered by the fact that a significant contribution on the mass peaks $m / z=15$ and 16 originates from other ions: organic fragments $\left(\mathrm{CH}_{3}^{+}\right)$on $m / z=15$ and $\mathrm{O}^{+}$on $m / z=16$ (Allan, Bower et al., 2004). Since the ion count rate on $m / z=16\left(\mathrm{I}_{16}\right)$ is by a factor of 10 higher than $\mathrm{I}_{15}$ (Allan, Bower et al., 2004), we prefer to use $\mathrm{I}_{16}$ for ammonium detection. 
We used a segment of the upper flight level on the first measurement flight that was not influenced by air traffic exhaust to obtain a statistically significant time period without particles, in order to determine the contribution of gas-phase compounds to $\mathrm{I}_{16}$. $\mathrm{I}_{16}$ adds up from $\mathrm{NH}_{2}^{+}(\mathrm{p}), \mathrm{O}^{+}(\mathrm{g})$, and $\mathrm{O}^{+}(\mathrm{p}) . \mathrm{O}^{+}(\mathrm{g})$ is due to fragmentation of gas phase $\mathrm{O}_{2}$ and $\mathrm{H}_{2} \mathrm{O}$ molecules, while $\mathrm{O}^{+}(\mathrm{p})$ originates from fragmentation products of particle bound water, sulfate, and organics. In an air mass with a negligible amount of aerosol mass, we can therefore determine the amount of gas-phase contributions to $m / z=16$. This contribution was determined to $0.353 \times \mathrm{I}_{14}$ (ion count rate of $m / z=14$ ). $m / z=14$ is assumed to be mainly composed of $\mathrm{N}^{+}$ions from fragmentation of $\mathrm{N}_{2}^{+}$with a very small contribution of particulate nitrate, which can be neglected during this part of the flight. This result was used to infer the gas-phase contribution to $\mathrm{I}_{16}$ for all altitudes, and the gas phase was subtracted from $\mathrm{I}_{16}$ before calculating the ammonium mass concentration.

In the ToF-mode, the gas-phase signal of $\mathrm{O}^{+}$has to be subtracted from the total signal of $m / z=16$ since it contributes to a significant amount to the size distribution. This contribution can be identified since gas molecules reach the ionizer much faster than the smallest aerosol particles that the AMS can detect.

\section{Results and discussion}

\subsection{Vertical profiles}

Fig. 5 gives the vertical profiles of the measured species sulfate, nitrate, organics and ammonium for the flights on 12 May 2003 (upper panel), 14 May 2003 (lower panel). Plotted are the one-minute raw data plus an averaged profile, for which the data have been binned into height intervals, with the displayed values representing the mean values inside these bins, and the bars denote the standard deviation. The mass concentrations refer to ambient conditions, i.e. not to standard pressure. The right panel gives the ambient air temperature.

On 12 May the temperature profile reveals as small inversion around $4 \mathrm{~km}$. In the aerosol mass concentrations the upper edge of the planetary boundary layer (PBL) is marked by a sharp decrease in nitrate and ammonium concentration at $3 \mathrm{~km}$ altitude, while the sulfate and organic mass concentration is decreasing with a smaller slope. This reflects the formation of sulfate and possibly also organic aerosol from sulfur-containing precursor gases in the free troposphere, while nitrate and ammonium have their sources only at the surface. On 14 May, the PBL is less pronounced: ammonium and nitrate reach up to $5 \mathrm{~km}$, most likely due to higher convective activity on this day. Temperatures are markedly colder than on 12 May, especially above $4 \mathrm{~km}$.

The mean values and standard deviations for the non-refractory aerosol mass components in the PBL, middle and upper troposphere are given in Table 2. Also, the relative contributions of the 4 components to the total measured mass concentration inside the PBL are displayed in Fig. 6 . These values are comparable with ground-based measurements taken almost exactly 1 year earlier (HAZE campaign, 18 May-1 June 2002) on the mountain "Hohenpeißenberg" (1000 m a.s.1.) which lies within $50 \mathrm{~km}$ of the airport (Hock et al., 2005).

Above $6 \mathrm{~km}$, the aerosol mass concentration decreases down to the detection limit of the AMS (see Table 1). Several improvements (e.g. higher inlet flow, better vacuum conditions) are planned in order to overcome this drawback in future aircraft missions in the upper troposphere. 

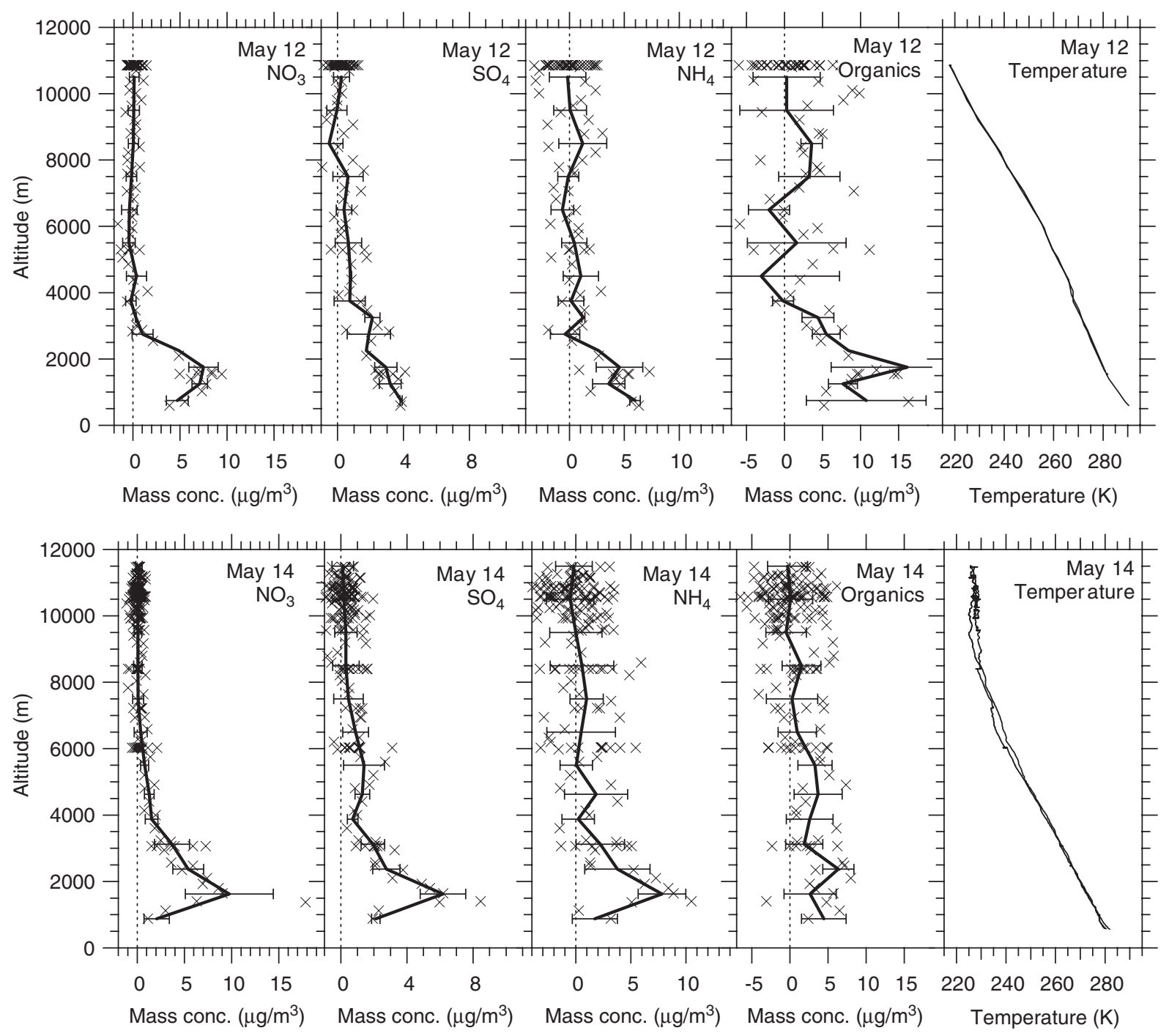

Fig. 5. Vertical profiles of nitrate, sulfate, ammonium, and organics along with temperature measured during the flights on 12 and 14 May 2003. The mass concentrations refer to ambient conditions.

In order to investigate if the aerosol sulfate and nitrate was fully neutralized by ammonium, we calculated the expected ammonium mass concentration assuming full neutralization, and compared this with the actual measured ammonium (Fig. 7). On both days, the measured ammonium inside the PBL is higher than the expected ammonium, indicating the boundary layer aerosol is basic, not acidic. Above the PBL, the aerosol is fully neutralized, within the error limits, which are large for the measured ammonium. No indication for excess sulfate was found, which would be expected if sulfuric acid aerosol was prevailing in the free troposphere.

The data reported by Lee et al. (2003) and Kline et al. (2004) from the TRACE-P and ACE-ASIA projects resemble the vertical profiles that we obtained over Southern Germany: High aerosol mass 
Table 2

Mean values and standard deviations $(\sigma)$ of the measured aerosol compounds in the boundary layer, in the middle and upper free troposphere

\begin{tabular}{|c|c|c|c|c|c|c|c|c|}
\hline Altitude (m) & $\mathrm{NO}_{3}$ & $\sigma$ & $\mathrm{SO}_{4}$ & $\sigma$ & $\mathrm{NH}_{4}$ & $\sigma$ & Organics & $\sigma$ \\
\hline \multicolumn{9}{|l|}{ May 12} \\
\hline 0-3000 (PBL) & 5.59 & 2.81 & 2.82 & 0.96 & 3.43 & 2.62 & 11.08 & 7.86 \\
\hline $3000-8000$ & -0.16 & 0.69 & 0.75 & 0.79 & 0.24 & 1.15 & 0.90 & 5.59 \\
\hline $8000-12000$ & 0.13 & 0.51 & 0.14 & 0.57 & -0.03 & 1.7 & 0.54 & 4.48 \\
\hline \multicolumn{9}{|l|}{ May 14} \\
\hline $0-5000(\mathrm{PBL})$ & 4.47 & 3.70 & 2.67 & 1.99 & 3.21 & 3.24 & 3.20 & 2.94 \\
\hline $5000-8000$ & 0.36 & 0.65 & 0.85 & 0.90 & 0.54 & 2.52 & 1.12 & 2.80 \\
\hline $8000-12000$ & 0.08 & 0.40 & 0.20 & 0.68 & -0.25 & 2.24 & 0.08 & 2.81 \\
\hline
\end{tabular}

The boundary layer was estimated to end at $3000 \mathrm{~m}$ on 12 May and at $5000 \mathrm{~m}$ on 14 May. The mass concentrations are given in $\mu \mathrm{g} / \mathrm{m}^{3}$ referring to ambient conditions.
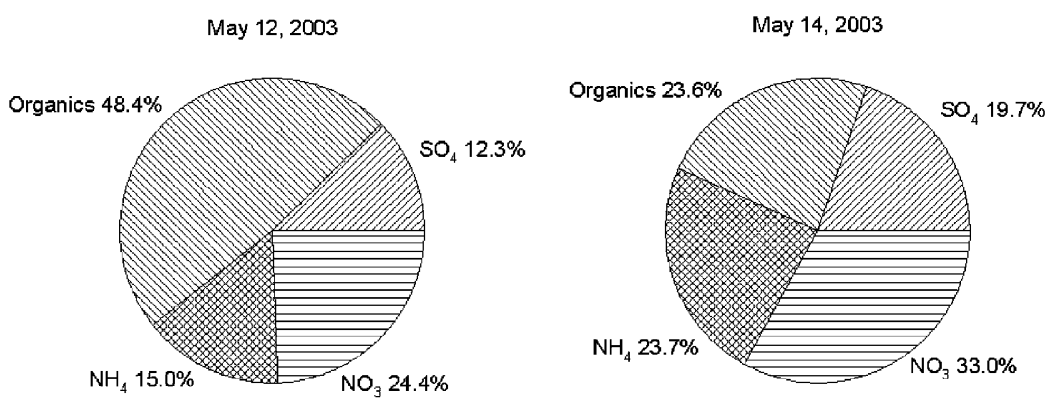

Fig. 6. Relative contributions (per cent by mass) of the individual non-refractory aerosol compounds to the boundary layer aerosol (12 May 2003: 0-3000 m; 14 May 2003: 0-5000 m).

concentrations in the boundary layer, and relatively sharp decrease to values almost as low as zero above. However, over East Asia, Lee et al. (2003) observed a 30\% deficit in $\mathrm{NH}_{4}$ when calculating the expected ammonium from the measured sulfate and nitrate. Bahreini et al. (2003) observed during their aircraftborne AMS measurements that the aerosol below $1000 \mathrm{~m}$ was not fully neutralized by ammonium, while above $1000 \mathrm{~m}$, and even more at altitudes above $3000 \mathrm{~m}$, excess $\mathrm{NH}_{4}$ was present in the aerosol. That our data show excess aerosol ammonium in the boundary layer may be due to different emission sources in Southern Germany (agricultural land use).

\subsection{Size-resolved chemical composition}

During ascent and descent through the lower levels of the atmosphere, the aircraft remained a certain time on one constant altitude, in order to sample representative size distributions on that altitude level. These levels were $1500 \mathrm{~m}$ on 12 May 3000 and $6000 \mathrm{~m}$ on 14 May. Sampling times were $4 \mathrm{~min}$ at $1500 \mathrm{~m}$, $4 \mathrm{~min}$ at $3000 \mathrm{~m}$, and $8 \mathrm{~min}$ on $6000 \mathrm{~m}$, corresponding to a sampled air volume in the ToF-mode of 168 , 210 , and $420 \mathrm{~cm}^{3}$, and to a horizontal flight distance of 30,36 , and $88 \mathrm{~km}$, respectively. The averaged 

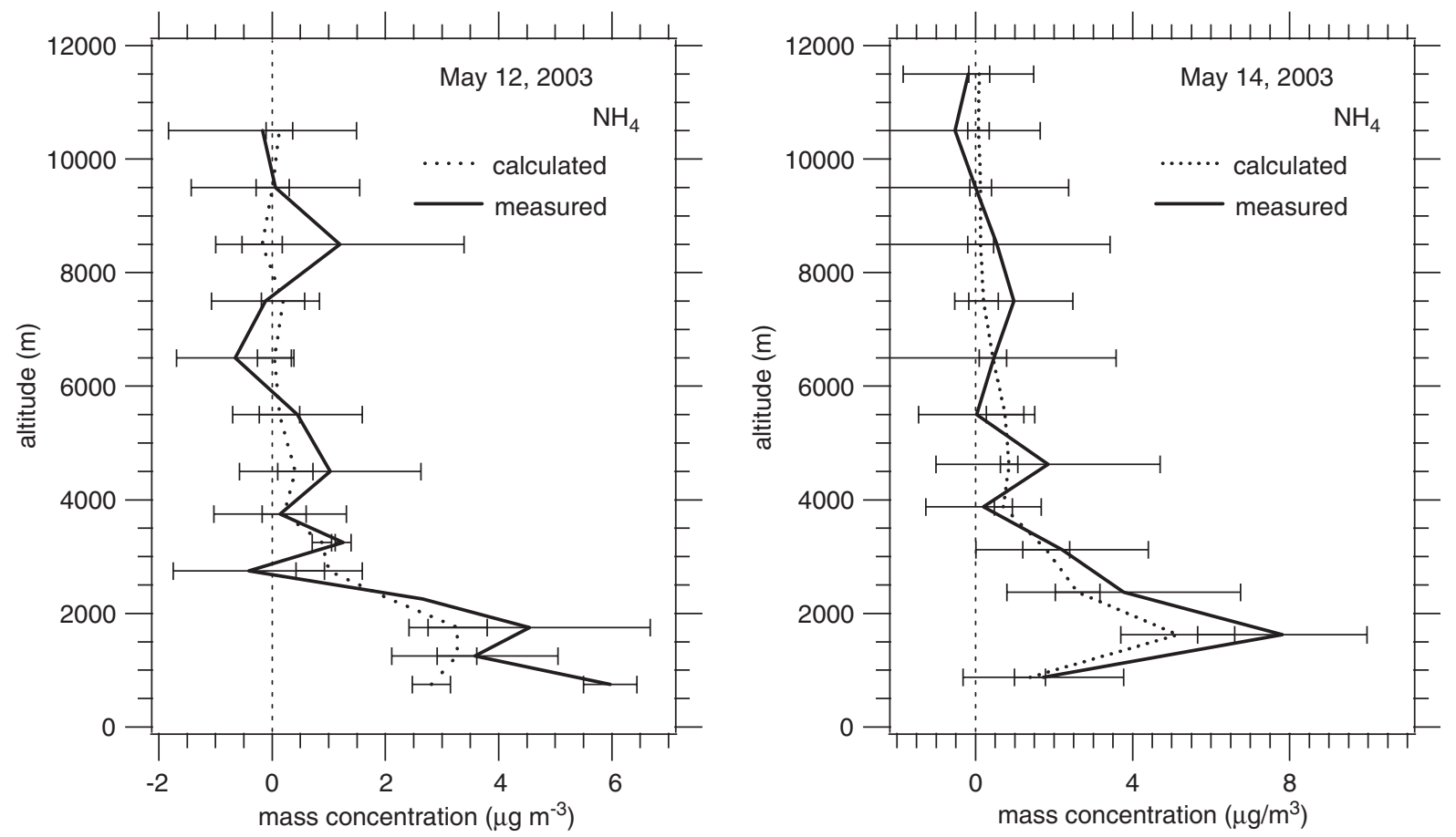

Fig. 7. $\mathrm{NH}_{4}$ measured versus $\mathrm{NH}_{4}$ calculated by $M\left(\mathrm{NH}_{4}\right)=2 \mathrm{MW}_{\mathrm{NH}_{4}} / \mathrm{MW}_{\mathrm{SO}_{4}} M\left(\mathrm{SO}_{4}\right)+\mathrm{MW}_{\mathrm{NH}_{4}} / \mathrm{MW}_{\mathrm{NO}_{3}} M\left(\mathrm{NO}_{3}\right)$ from the measured $\mathrm{NO}_{3}$ and $\mathrm{SO}_{4}$ values. $M$ : mass concentration, $\mathrm{MW}$ : molar weight.

mass size distributions are displayed in Fig. 8. The data have been grouped into 20 size bins, and the error bars denote the standard deviations inside the individual size bins.

The mass size distributions have been fitted using mono-, bi-, and trimodal lognormal distributions. At $1.5 \mathrm{~km}$ (12 May), it appears that the nitrate, sulfate and ammonium distributions have a common mode with a modal diameter of $500 \mathrm{~nm}$, which indicates an internal mixture. The mode at $200 \mathrm{~nm}$ consists of organics and nitrate (no ammonium, so most likely organic nitrate), and the mode at $90 \mathrm{~nm}$ consists of ammonium sulfate.

The mass size distributions measured on 14 May at 3 and $6 \mathrm{~km}$ look different and noisier. At $6 \mathrm{~km}$, one internal mixed mode consisting of sulfate, ammonium and organics is found at a modal diameter of $100 \mathrm{~nm}$, but the clear bimodal structure of sulfate is not found in ammonium and organics. The nitrate mass concentration at $6 \mathrm{~km}$ was below the detection limit for size distributions. At $3 \mathrm{~km}$, nitrate dominates with a monomodal distribution at a modal diameter of $300 \mathrm{~nm}$. The organics show a bimodal structure with one mode at $90 \mathrm{~nm}$ and the other at $1000 \mathrm{~nm}$. The sulfate trimodal fit is regarded to be unrealistic since the modes are too narrow, and the ammonium signal is too noisy to generate meaningful fit curves. Generally the mass distribution of sulfate, ammonium, and organics at 3 and $6 \mathrm{~km}$ altitude have to be taken with care since the amount of particles analyzed during the sampling periods are limited. The ammonium mass distribution was obtained from one $m / z$ (16), sulfate and nitrate on two $m / z$ ratios (30, 46 and 48, 64 , respectively) while the organic mass distribution was determined on five $m / z$ ratios. This means that to obtain the mass distribution of organics five times more particles have been sampled than for the mass 

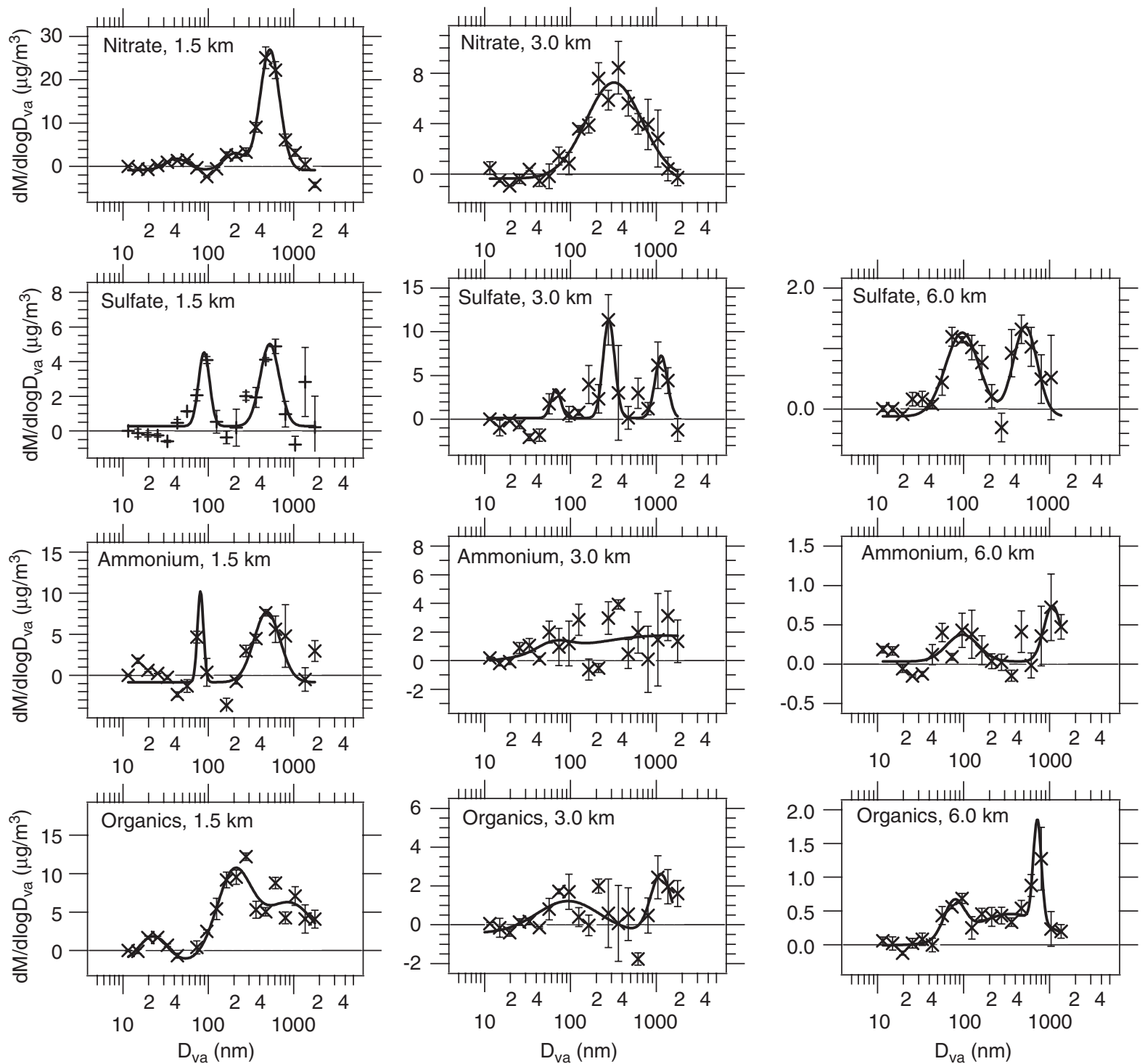

Fig. 8. Size distributions of nitrate, sulfate, ammonium and organics for three different altitudes. Data have been binned in 20 size bins, the bars denote the standard deviation inside the bins. The size distributions have been fitted with mono-, bi- and trimodal lognormal distributions. The data measured at $1.5 \mathrm{~km}$ (left panel) have been taken on 12 May 2003, the other on 14 May 2003 . Nitrate data were below the detection limit at $6 \mathrm{~km}$.

distribution of ammonium. From the above-mentioned sampling volumes together with the duty cycle of the AMS in the ToF-mode (2\%) and the measured particle concentrations (see next section) it follows that the ammonium mass size distribution was inferred from only 73 particles at $6 \mathrm{~km}$ altitude and from 280 particles at $3 \mathrm{~km}$ altitude. 


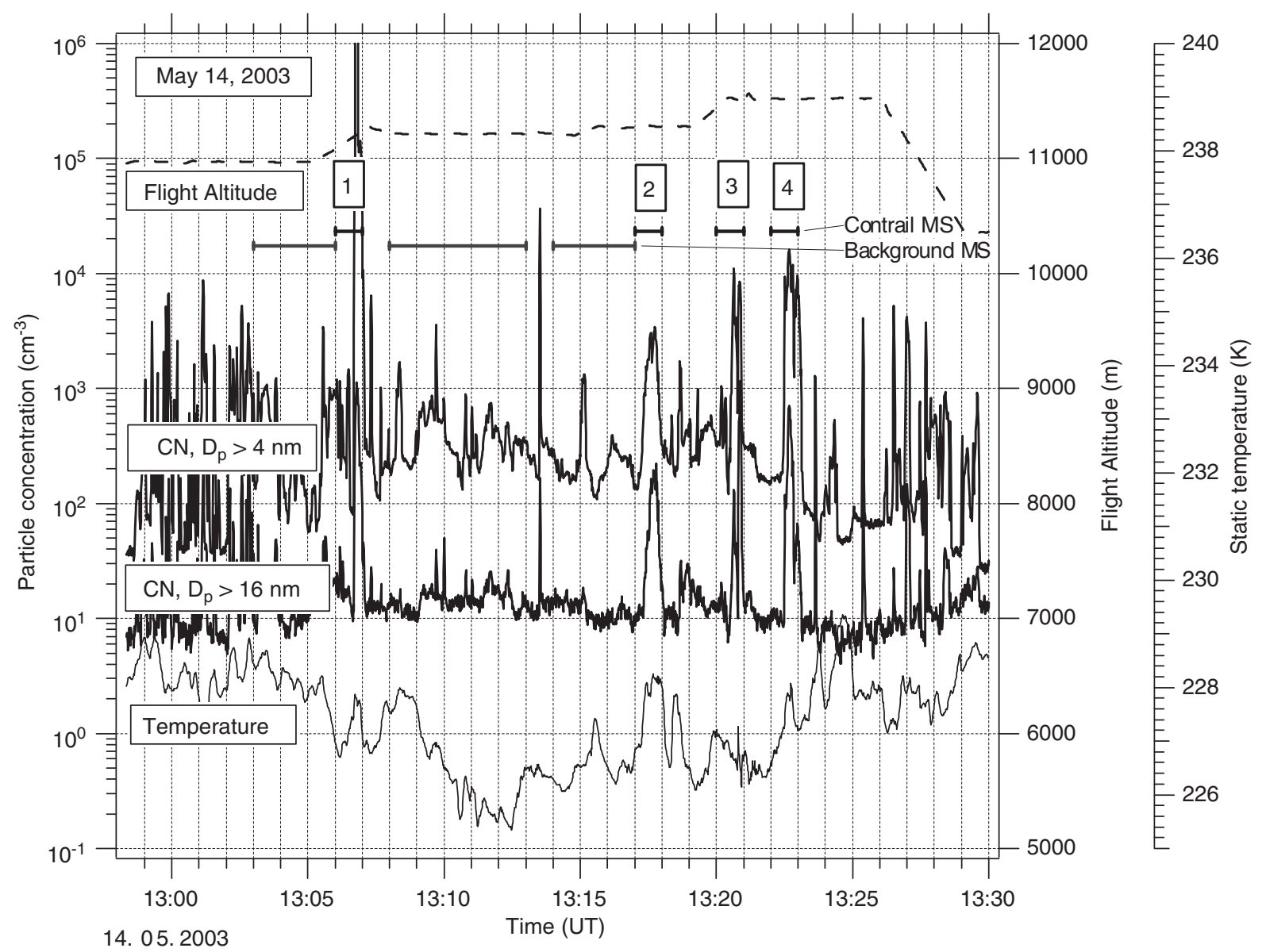

Fig. 9. Aircraft chasing episode during the flight on 14 May. The contrail sampling times can be identified by the particle number concentrations measured by the two $\mathrm{CN}$ counters, and by the temperature peaks also used to infer the plume ages.

\subsection{Aircraft exhaust measurements}

During the measurement flight on 14 May, several short encounters with exhaust plumes of commercial jet aircraft were achieved. The individual plume penetrations were identified by the particle number density, measured with two condensation particle counters with lower cut-off diameters of 4 and $16 \mathrm{~nm}$, respectively. Fig. 9 gives the particle concentration data for the flight segment of the flight on 14 May when the aircraft chasing took place.

Also given in Fig. 9 is the temperature measured by the Falcon data acquisition system. These can be used to estimate the plume age (Schumann et al., 1998). For the contrail events \#1, \#2, and \#4, the following values for the temperature deviations from the background $(\Delta T)$ were inferred: $0.90,1.7$, and $0.63 \mathrm{~K}$, respectively. Using the measured values reported by Schumann et al. (1998), we converted these $\Delta T$ s into plume ages: $3.3,1.9$, and $4.4 \mathrm{~s}$, respectively. For the contrail event \#3 no significant temperature increase could be inferred. 

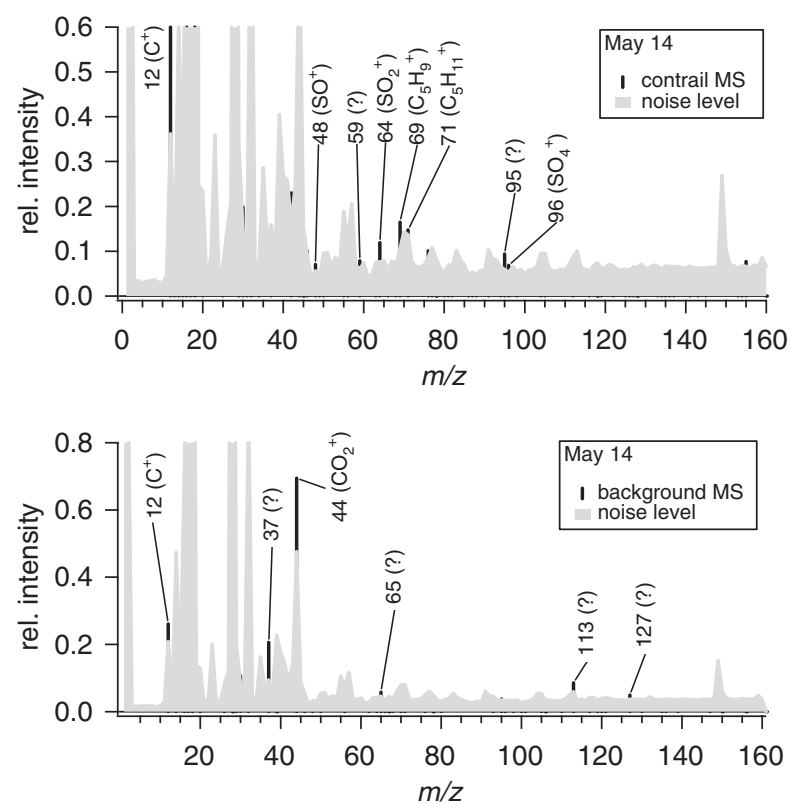

Fig. 10. Averaged mass spectra recorded during the contrail penetration episodes indicated in Fig. 9 (upper panel), together with averaged background mass spectrum (lower panel).

The black bars denote the sampling time resolution of the AMS. Since the plume penetrations have been very short (below $1 \mathrm{~min}$ ), all 4 plume events were averaged and compared with the background that was inferred from the flight phases between the plume events, as indicated by the gray bars. The AMS size range allows the measurement of soot particles, if they are coated with semi-volatile compounds, the small contrail ice crystals, and the entrained background particles, but not the ultrafine particles that are dominating the number density.

The averaged mass spectra recorded inside and outside the plumes are displayed in Fig. 10, together with the noise for both spectra. Since the background MS was averaged over a longer time span, the noise is lower. However, there are distinct peaks that are only present in the contrail MS and not in the background MS, and that are clearly higher than the noise level of the contrail MS. We attribute these peaks to aircraft exhaust, and have added suggestions for the composition.

Fig. 11 compares laboratory mass spectra with the mass spectrum recorded during the 4 aircraft plume penetrations: The upper mass spec (panel a) was obtained by burning Kerosene in a laboratory burner under low oxygen conditions. The mass spectrum shows the typical alkane fragmentation pattern $(\mathrm{m} / \mathrm{z}$ $27,29,41,43,55,57,69,71$, etc.), which can be identified as $\mathrm{C}_{n} \mathrm{H}_{2 n-1}^{+}$and $\mathrm{C}_{n} \mathrm{H}_{2 n+1}^{+}$, and is similar to those observed by Canagaratna et al. (2004) and Schneider et al. (2005) in Diesel exhaust. Besides these peaks, two prominent mass lines appeared (73 and 147), which are also dominant in the mass spec obtained from spark soot particles (panel b). The nature of these ions remains still unresolved. Panel (c) gives a mass spectrum that was obtained from sulfuric acid particles generated by a nucleation particle generator as described by Middlebrook, Thomson, and Murphy (1997).

The contrail MS (lowermost panel) contains mass peaks that correspond to the Kerosene combustion particle MS $(m / z=29,69,70,71)$, and also peaks that correspond to $\mathrm{H}_{2} \mathrm{SO}_{4}$ particles $(\mathrm{m} / z=64,80$, 

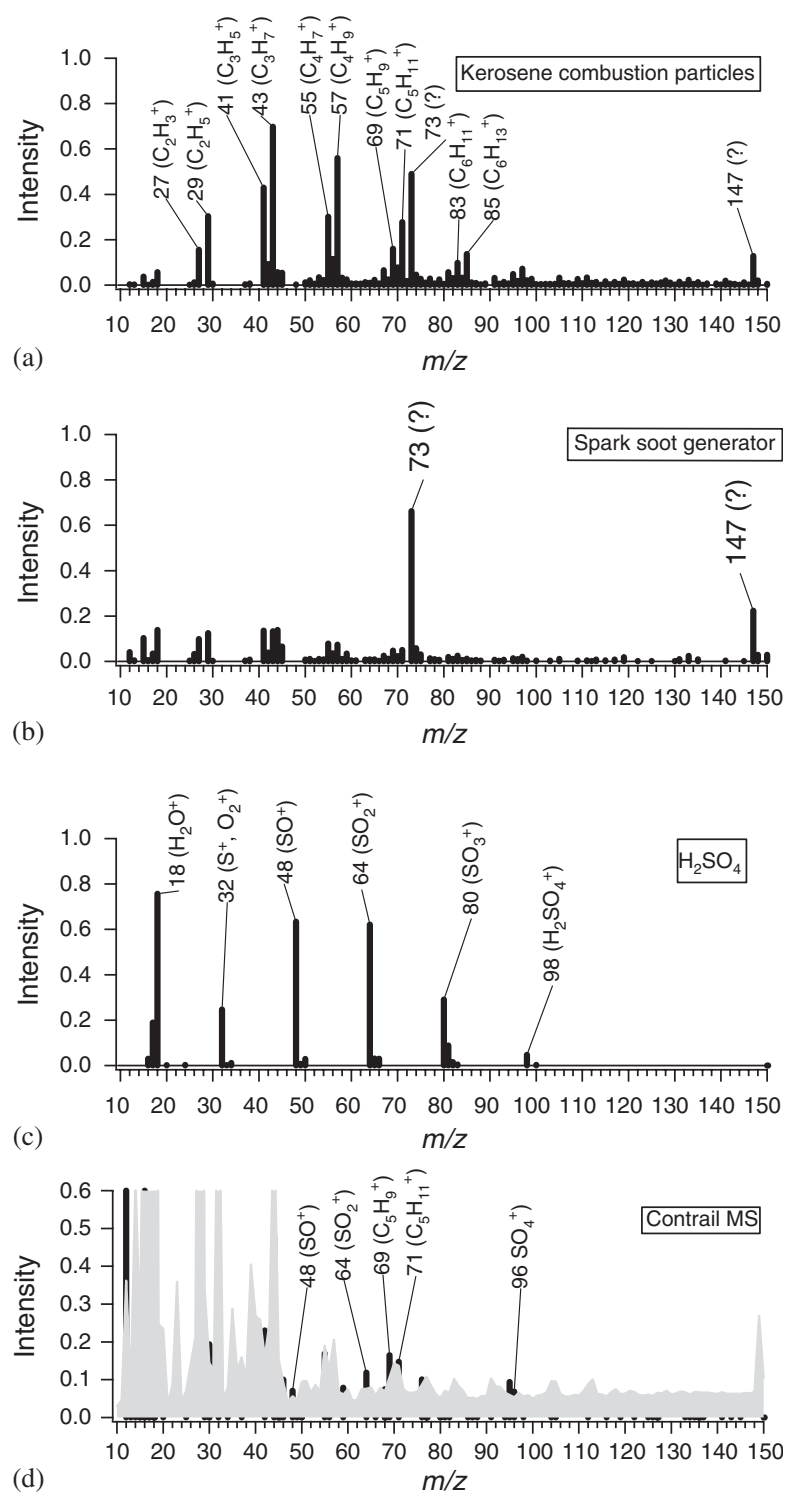

Fig. 11. Comparison of laboratory generated mass spectra from: (a) kerosene combustion particles, (b) spark soot particles, (c) sulfuric acid droplets, with the mass spectrum recorded in the aircraft exhaust (d).

possibly also $m / z=32$ ). This indicates that the exhaust particles (averaged over 4 plume penetrations) contained sulfuric acid as well as primary organics (hydrocarbons). The fragment $\mathrm{CO}_{2}^{+}(\mathrm{m} / z=44)$, which is associated with secondary (oxygenated) organics (Alfarra et al., 2004), was much more pronounced in the background mass spectrum than in the plume mass spectrum, indicating the presence of photochemically processed aerosol in the tropopause region, possibly due to aged aircraft emissions. 


\section{Summary and conclusion}

The Aerodyne quadrupole aerosol mass spectrometer (Q-AMS) was successfully deployed on the research jet aircraft Falcon. Aerosol measurements were performed between ground level and the tropopause. During two flights (12 and 14 May 2003), high quality data were be obtained.

The atmospheric conditions were markedly different between the two flights on 12 and 14 May 2003. On 12 May, a sharp boundary layer top at $3 \mathrm{~km}$ was found, and the boundary layer aerosol was composed to about $50 \%$ by mass of organics. Above the boundary layer, ammonium nitrate decreased sharply, while sulfate and organics decreased markedly slower.

The size distributions measured inside the PBL indicated that ammonium sulfate and -nitrate were internally mixed in the $500 \mathrm{~nm}$ mode, and the organics were externally mixed, with a modal diameter of $200 \mathrm{~nm}$, a mode that also contained organic nitrate. A smaller mode $(80 \mathrm{~nm})$ contained only ammonium sulfate.

On 14 May, the boundary layer reached up to $5 \mathrm{~km}$, without a clear distinction from the free troposphere, most likely due to more pronounced convective activity. Also, inside the boundary layer, the organic fraction was only about $25 \%$ by mass of the non-refractory fine mode aerosol.

The size distributions that were measured in the upper part of the boundary layer showed a monomodal nitrate distribution, and very noisy distributions of the other species.

Above the boundary layer $(6 \mathrm{~km})$, the nitrate size distribution was below the detection limit, while the ammonium sulfate distribution showed a bimodal structure with peaks at 100 and $600-800 \mathrm{~nm}$. The organic size distribution also peaks at about $100 \mathrm{~nm}$. Whether this ammonium sulfate size distribution is representative for the free troposphere at this time and location or whether it is influenced by boundary layer air due to convection on this specific day, cannot be stated definitely.

In the exhaust plume of commercial jet aircrafts at cruise altitude, which were sampled at plume ages between 1.9 and $4.4 \mathrm{~s}$, particles containing sulfuric acid and primary organics (hydrocarbons) were detected. Secondary, photochemically processed aerosol was detected in the background mass spectrum, but not in the plume. This indicates the presence of processed organic aerosol in the tropopause region, which might be due to aged primary organic components emitted by aircraft that have been photochemically processed and subsequently condensed on soot particles.

Generally, the background aerosol data presented here are restricted to altitudes below $6 \mathrm{~km}$. Above $6 \mathrm{~km}$, the aerosol mass concentrations decrease down to the detection limit of the Q-AMS under the operating conditions during the PAZI campaign. Several improvements are planned for future aircraft missions dedicated to higher altitudes: Increase of the inlet flow, better vacuum conditions, and usage of the novel ToF-AMS (Drewnick et al., 2005) that offers a significantly higher detection efficiency.

\section{Acknowledgements}

We thank T. Böttger, W. Schneider and the DLR Flight Department. Part of the data evaluation has been done with James Allan's AMS Analysis Toolkit. Financial contributions by the Max-Planck-Gesellschaft (MPG), the Johannes Gutenberg-University Mainz, and the Helmholtz-Gemeinschaft Deutscher Forschungszentren (HGF) are acknowledged. This study has been carried out as part of the DLR/HGF project PAZI. 


\section{References}

Alfarra, M. R., Coe, H., Allan, J. D., Bower, K. N., Boudries, H., Canagaratna, M. R. et al. (2004). Characterization of urban and rural organic particulate in the lower fraser valley using two Aerodyne aerosol mass spectrometers. Atmospheric Environment, $38,5745-5758$.

Allan, J. D., Bower, K. N., Coe, H., Boudries, H., Jayne, J. T., Canagaratna, M. R. et al. (2004). Submicron aerosol composition at Trinidad Head, California, during ITCT 2K2: Its relationship with gas phase volatile organic carbon and assessment of instrument performance. Journal of Geophysical Research, 109, D23S24.

Allan, J. D., Coe, H., Bower, K. N., Alfarra, M. R., Delia, A. E., Jimenez, J. L. et al. (2004). Technical note: Extraction of chemically resolved mass spectra from Aerodyne aerosol mass spectrometer data. Journal of Aerosol Science, 35, 909-922.

Allan, J. D., Jimenez, J. L., Williams, P. I., Alfarra, M. R., Bower, K. N., Jayne, J. T. et al. (2003). Quantitative sampling using an Aerodyne aerosol mass spectrometer 1. Techniques of data interpretation and error analysis. Journal of Geophysical Research, 108, 4090.

Bahreini, R., Jimenez, J. L., Wang, J., Jayne, J. T., Worsnop, D. R., Flagan, R. C. et al. (2003). Aircraft-based aerosol size and composition measurements during ACE-Asia using an Aerodyne aerosol mass spectrometer. Journal of Geophysical Research, 108, 8645.

Brock, C. A., Schröder, F., Kärcher, B., Petzold, A., Busen, R., \& Fiebig, M. (2000). Ultrafine particle size distribution measured in aircraft exhaust plumes. Journal of Geophysical Research, 105(D21), 26555-26567.

Canagaratna, M. R., Jayne, J. T., Ghertner, D. A., Herndon, S., Shi, Q., Jimenez, J. L. et al. (2004). Chase studies of particulate emissions from in-use New York city vehicles. Aerosol Science and Technology, 38, 555-573.

Curtius, J., Sierau, B., Arnold, F., Baumann, R., Busen, R., Schulte, P. et al. (1998). First direct sulfuric acid detection in the exhaust plume of a jet aircraft in flight. Geophysical Research Letters, 25, 923-926.

Dibb, J. E., Talbot, R. W., Lefer, B. L., Scheurer, E., Gregory, G. L., Browell, E. V. et al. (1997). Distributions of beryllium-7, lead-210, and soluble aerosol-associated ionic species over the western Pacific: PEM-West B, February-March, 1994. Journal of Geophysical Research, 102, 28287-28302.

Dibb, J. E., Talbot, R. W., \& Loomis, M. B. (1998). Tropospheric sulfate distribution during SUCCESS: Contributions from jet exhaust and surface sources. Geophysical Research Letters, 25, 1375-1378.

Dibb, J. E., Talbot, R. W., Scheurer, E. M., Blake, D. R., Blake, N.-J., Gregory, G. L. et al. (1999). Aerosol chemical composition and distribution during the Pacific Exploratory Mission, Tropics. Journal of Geophysical Research, 104, 5785-5800.

Drewnick, F., Hings, S. S., DeCarlo, P., Jayne, J. T., Gonin, M., Fuhrer, K., et al. (2005). A new time-of-flight aerosol mass spectrometer (TOF-AMS) - instrument description and first field deployment. Aerosol Science and Technology, in press.

Drewnick, F., Schwab, J. J., Hogrefe, O., Peters, S., Husain, L., Diamond, D. et al. (2003). Intercomparison and evaluation of four semi-continuous PM2.5 sulfate instruments. Atmospheric Environment, 37, 3335-3350.

Ettner, M., Mitra, S. K., \& Borrmann, S. (2004). Homogeneous freezing of single sulfuric acid solution droplets: Laboratory experiments utilizing an acoustic levitator. Atmospheric Chemistry \& Physics, 4, 1925-1932.

Fiebig, M. (2001). The tropospheric aerosol at mid-latitudes-microphysics, optics, and climate forcing illustrated by the LACE 98 field study. Ph.D. thesis (in German), University of Munich, Munich, Germany.

Hock, N., Schneider, J., Berresheim, H., Römpp, A., Pöschl, U., \& Borrmann, S. (2005). The Hohenpeißenberg aerosol characterization experiment (HAZE2002): Aerosol composition derived from mass spectrometry. Atmospheric Chemistry and Physics, to be submitted.

Hogrefe, O., Drewnick, F., Lala, G. G., Schwab, J. J., \& Demerjian, K. L. (2004). Development, operation and applications of an aerosol generation, calibration and research facility. Aerosol Science and Technology, 38, 196-214.

Huffman, J. A., Jayne, J. T., Drewnick, F., Aiken, A. C., Onasch, T., Worsnop, D. R., et al. (2005). Design, modeling, optimization, and experimental tests of a particle beam width probe for the Aerodyne aerosol mass spectrometer. Aerosol Science and Technology, submitted for publication.

Jayne, J. T., Leard, D. C., Zhang, X., Davidovits, P., Smith, K. A., Kolb, C. E. et al. (2000). Development of an aerosol mass spectrometer for size and composition analysis of submicron particles. Aerosol Science and Technology, 33, 49-70.

Jimenez, J. L., Bahreini, R., Cocker, R. R., Zhuang, H., Varutbangkul, V., Flagan, R. C. et al. (2003). New particle formation from photooxidation of diiodomethane $\left(\mathrm{CH}_{2} \mathrm{I}_{2}\right)$. Journal of Geophysical Research, 108(D10), 4318.

Jimenez, J. L., Jayne, J. T., Shi, Q., Kolb, C. E., Worsnop, D. R., Yourshaw, I. et al. (2003). Ambient aerosol sampling with an aerosol mass spectrometer. Journal of Geophysical Research, 108(D7), 8425. 
Kärcher, B., Yu, F., Schröder, F. P., \& Turco, R. P. (1998). Ultrafine aerosol particles in aircraft plumes: Analysis of growth mechanisms. Geophysical Research Letters, 25(15), 2793-2796.

Kline, J., Huebert, B., Howell, S., Blomquist, B., Zhuang, J., Bertram, T. et al. (2004). Aerosol composition versus altitude measured from the C-130 during ACE-Asia. Journal of Geophysical Research, 109, D19S08.

Lee, Y.-N., Weber, R., Ma, Y., Orsini, D., Maxwell-Meier, K., Blake, D. et al. (2003). Airborne measurements of inorganic ionic components of fine aerosol particles using the particle-into-liquid sampler coupled to ion chromatography technique during ACE-Asia and TRACE-P. Journal of Geophysical Research, 108(D23), 8646.

Middlebrook, A. M., Thomson, D. S., \& Murphy, D. M. (1997). On the purity of laboratory-generated sulfuric acid droplets and ambient particles studied by laser mass spectrometry. Aerosol Science and Technology, 27, 293-307.

Moore, K. G., II., Clarke, A. D., Kapustin, V. N., McNaughton, C., Anderson, B. E., Winstead, E. L. et al. (2004). A comparison of similar aerosol measurements made on the NASA P3-B, DC-8, and NSF C-130 aircraft during TRACE-P and ACE-Asia. Journal of Geophysical Research, 109, D15S15.

Murphy, D. M., Thomson, D. S., \& Mahoney, M. J. (1998). In situ measurements of organics, meteoritic material, mercury, and other elements in aerosols at 5-19 km. Science, 282, 1664-1669.

Petzold, A., Busen, R., Schröder, F. P., Baumann, R., Kuhn, M., Ström, J. et al. (1997). Near-field measurements on contrail properties from fuels with different sulfur content. Journal of Geophysical Research, 102(D23), 29867-29880.

Schneider, J., Borrmann, S., Wollny, A. G., Bläsner, M., Mihalopoulos, N., Oikonomou, K. et al. (2004). Online mass spectrometric aerosol measurements during the MINOS campaign (Crete, August 2001). Atmospheric Chemistry and Physics, 4, 65-80.

Schneider, J., Hock, B. N., Weimer, S., Borrmann, S., Kirchner, U., Vogt, R., et al. (2005). Nucleation particles in diesel exhaust: Composition inferred from in-situ mass spectrometric analysis. Environmental Science and Technology, in press, doi:10.2021/es049427m.

Schröder, F., Brock, C. A., Baumann, R., Petzold, A., Busen, R., Schulte, P. et al. (2000). In situ studies on volatile jet exhaust particle emissions: Impact of fuel sulfur content and environmental conditions on nuclei mode aerosols. Journal of Geophysical Research, 105, 19941-19954.

Schumann, U., Arnold, F., Busen, R., Curtius, J., Kärcher, B., Kiendler, A. et al. (2002). Influence of fuel sulfur on the composition of aircraft exhaust plumes: The experiments SULFUR 1-7. Journal of Geophysical Research, 107(D15), 4247.

Schumann, U., Schlager, H., Arnold, F., Baumann, R., Haschberger, P., \& Klemm, O. (1998). Dilution of aircraft exhaust plumes at cruise altitudes. Atmospheric Environment, 32, 3097-3103.

Seinfeld, J. H., \& Pandis, S. N. (1998). Atmospheric chemistry and physics. New York: Wiley.

Yu, F., Turco, R. P., Kärcher, B., \& Schröder, F. P. (1998). On the mechanisms controlling the formation and properties of volatile particles in aircraft wakes. Geophysical Research Letters, 25, 3839-3842.

Zhang, X., Smith, K. A., Worsnop, D. R., Jimenez, J. L., Jayne, J. T., Kolb, C. E. et al. (2004). Characterization of particle beam collimation: Part II integrated aerodynamic lens-nozzle system. Aerosol Science and Technology, 38, 619-638. 